\title{
Sensation of Balance Dysregulation Caused/Aggravated by a Collection of Electromagnetic Waves in a Dental Implant
}

\author{
Yoshiro Fujii \\ Shin Kobe Dental Clinic, Kobe City, Japan \\ Email: shin-kobe-dentalclinic@s9.dion.ne.jp
}

Received 17 July 2014; revised 25 August 2014; accepted 17 September 2014

Copyright (C) 2014 by author and Scientific Research Publishing Inc.

This work is licensed under the Creative Commons Attribution International License (CC BY). http://creativecommons.org/licenses/by/4.0/

(c) (i) Open Access

\begin{abstract}
Cell phone and personal computer users have increased considerably in recent years, particularly in more developed countries. These devices have facilitated communication on a global scale. However, there have been a number of reports of abnormalities occurring in the body due to the electromagnetic waves emitted by such electronic devices. The long lists of both general and severe symptoms, including headaches, fatigue, tinnitus, dizziness, memory loss, irregular heartbeat, and whole-body skin symptoms, have been reported that are apparently associated with the condition of electromagnetic hypersensitivity. In dentistry, titanium dental implants may be commonly associated with antenna-like activity, but the underlying mechanism remains unknown. In the current case studies, balance difficulties were found to occur when the patients had titanium dental implants. These implants seemed to be acting as antennae and collecting harmful electromagnetic waves. Further studies are required to confirm this hypothesis.
\end{abstract}

\section{Keywords}

Electromagnetic Hypersensitivity, Titanium Dental Implant, Balance Dysregulation

\section{Introduction}

The use of electronic devices, such as cell phones or personal computers (PCs), has become increasingly widespread in recent years [1] [2]. Through the development and increased usage of these electronics, quick communication has been enabled on a worldwide scale. However, there are a number of reports of abnormalities occurring in the body caused by the electromagnetic waves emitted by electronic devices, such as cell phones [3]-[10], and it is possible that the incidence of adverse biological effects caused by electromagnetic waves may be in- 
creasing. Such physically unpleasant symptoms are called electromagnetic hypersensitivity. There are many general and severe symptoms, such as headaches, fatigue, tinnitus, dizziness, memory loss, irregular heartbeats, and whole-body skin symptoms, which are considered to be caused by electromagnetic hypersensitivity [11][15]. In this article, the author described a sense of balance in difficulties that appeared to be caused or promoted by electromagnetic waves collected by dental implants through two case reports.

\section{Case Reports}

\subsection{Case Report 1}

\section{Treatment and Results}

A 48-year-old woman was suffering from dizziness, unsteadiness, and a sense of fatigue for several years. A titanium dental implant had been placed in her lower alveolar bone (Figure 1). To determine if the patient's symptoms were being caused by her implant's collection of electromagnetic waves, several tests were performed. First, the patient was placed immediately in front of a PC screen. At such a close distance, she could not maintain her balance (Figure 2). When the PC screen was covered with aluminum foil to block the electromagnetic

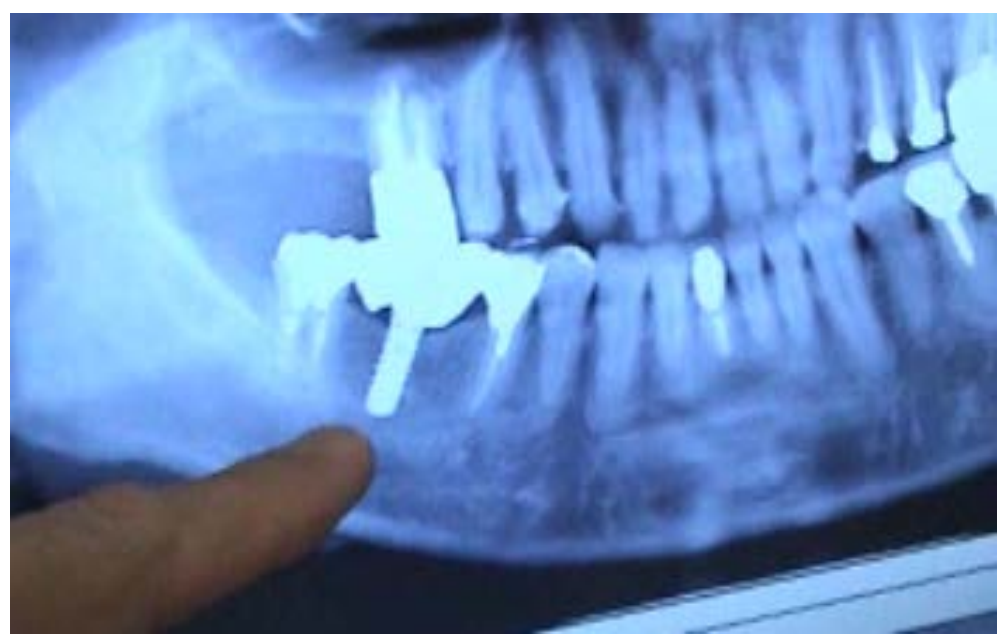

Figure 1. The titanium implant in the subject's right lower alveolar bone.

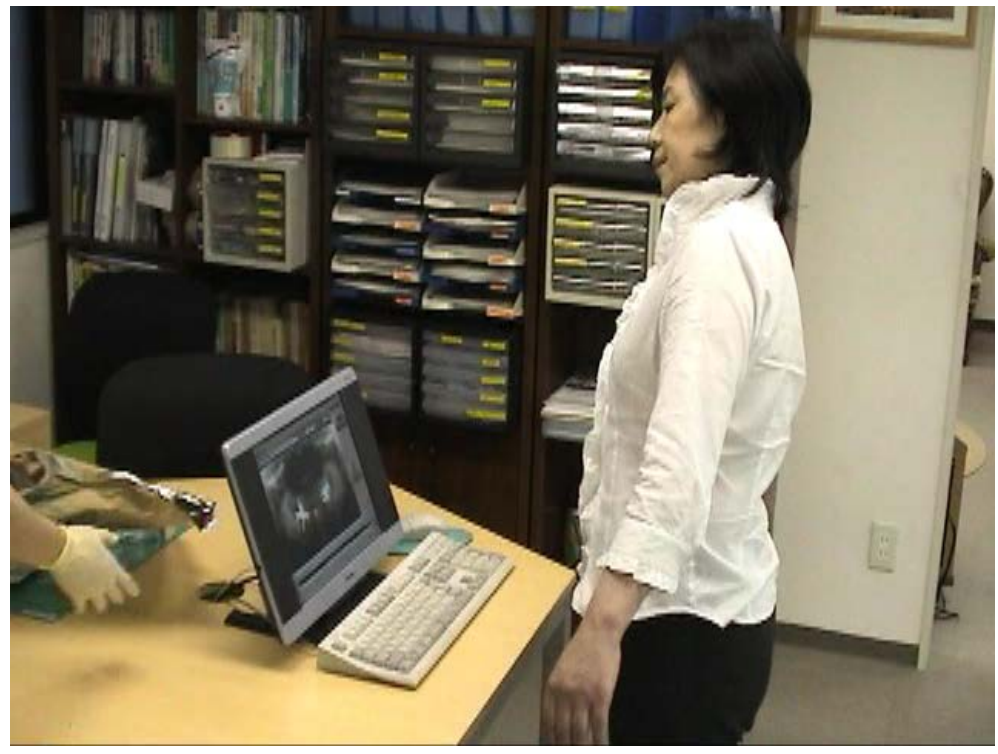

Figure 2. The subject became unsteady in front of a computer and could not maintain her balance. 
waves emitted by the screen, the patient was able to regain her balance. Second, the patient was asked to move away from the PC until she was able to maintain her balance. She was able to remain steady when standing about $3 \mathrm{~m}$ away from the PC. Third, a second titanium implant, which was of similar manufacture, was placed on the floor immediately in front of her feet. Under this condition, the patient lost her balance again (Figure 3), and reported experiencing dizziness and dyspnea. Finally, when the PC screen was covered with aluminum foil again, she was able to regain her balance, and reported no dizziness or dyspnea. These results seemed to indicate that the patient's implant was collecting electromagnetic waves, which were adversely affecting her. Consequently, her implant was removed. After the procedure, the first test was repeated. This time, when the patient stood close to the PC screen, she was able to maintain her balance (Figure 4). However, when the removed implant was placed on the table holding the PC, which was immediately in front of her, the symptoms returned. The conditions which suffered her have not recurred for three years or more.

In conclusion, removal of her implant resulted in a marked improvement in her sensitivity to electromagnetic waves. This finding suggests that certain materials in our bodies can collect harmful electromagnetic waves that

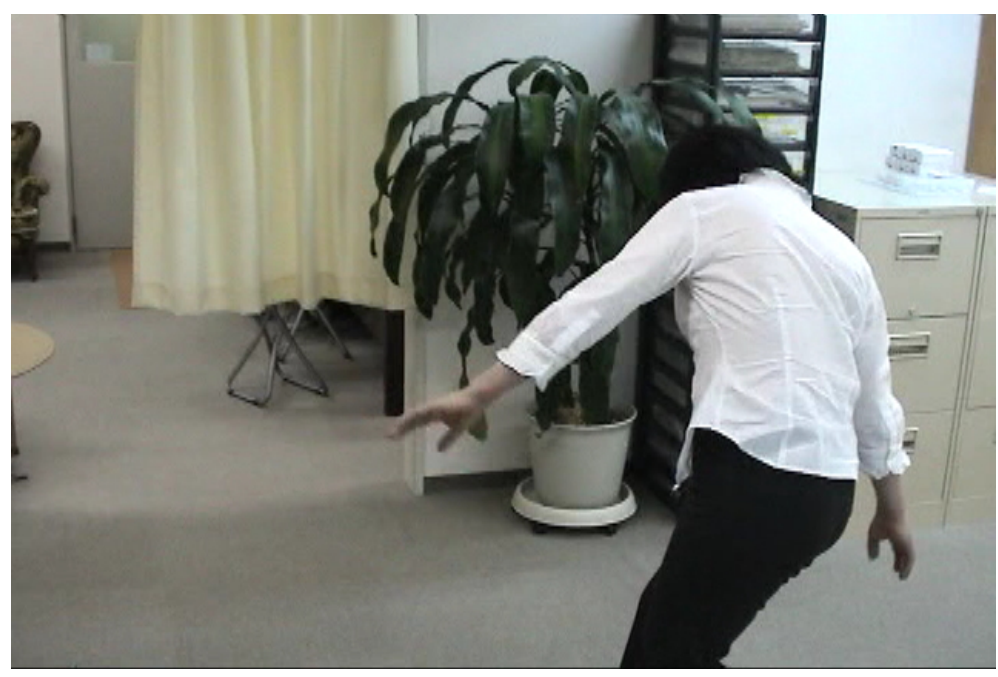

Figure 3. The patient falling after the second implant was placed on the floor in front of her while she stood about $3 \mathrm{~m}$ away from the personal computer screen.

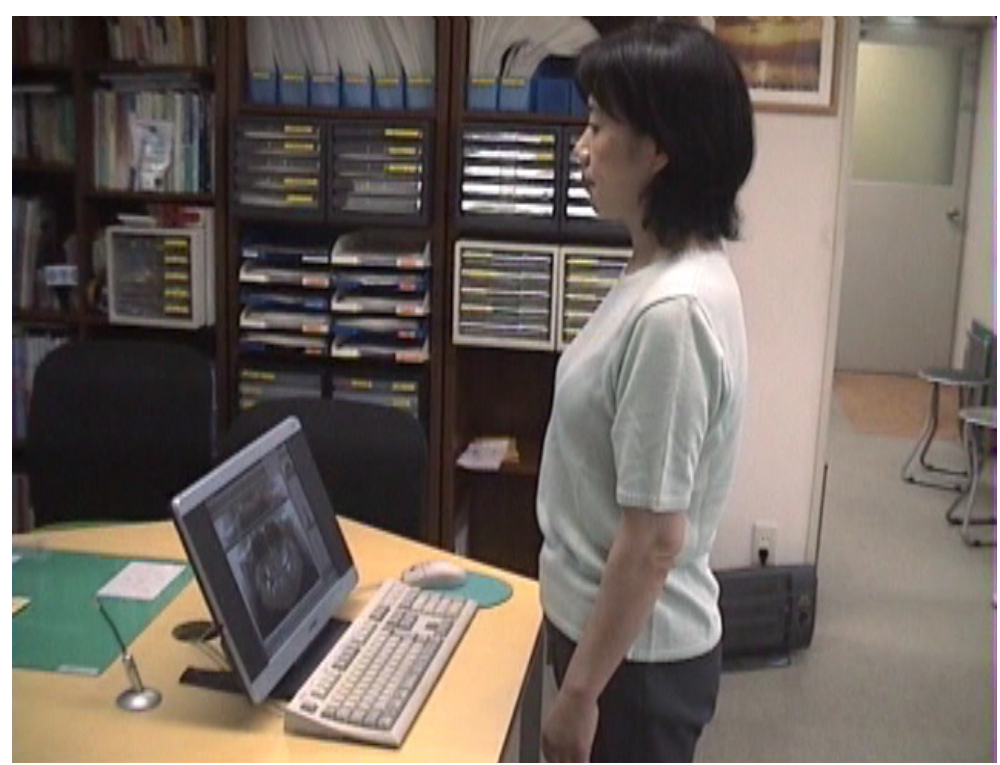

Figure 4. The subject standing stably and maintaining her balance in front of the personal computer after implant removal. 
can exert adverse effects. These harmful electromagnetic waves are emitted not only by cell phones but also by PC screens. The titanium implant in the present case appeared to interact with electromagnetic waves and adversely affect the patient's balance even when the implant was not present in or on the patient's body.

This patient gave consent to having the results of treatment published.

The details of this case can be observed in the following YouTube video.

Unsteadiness and dizziness caused by a dental implant.

https://www.youtube.com/watch?v=6IJFZeht84I (last checked 2 May 2014).

\subsection{Case Report 2}

\section{Subject and Experiment}

A woman in her twenties experienced a loss of balance when a cell phone was held at a distance $<50 \mathrm{~cm}$ from her body (Figure 5). The patient's medical history was unknown because she was a volunteer who was selected from an audience during one of the author's lectures. When a titanium implant was placed on her chest, she leaned backward, although the distance between the subject and the cell phone still exceeded $3 \mathrm{~m}$ (Figure 6).

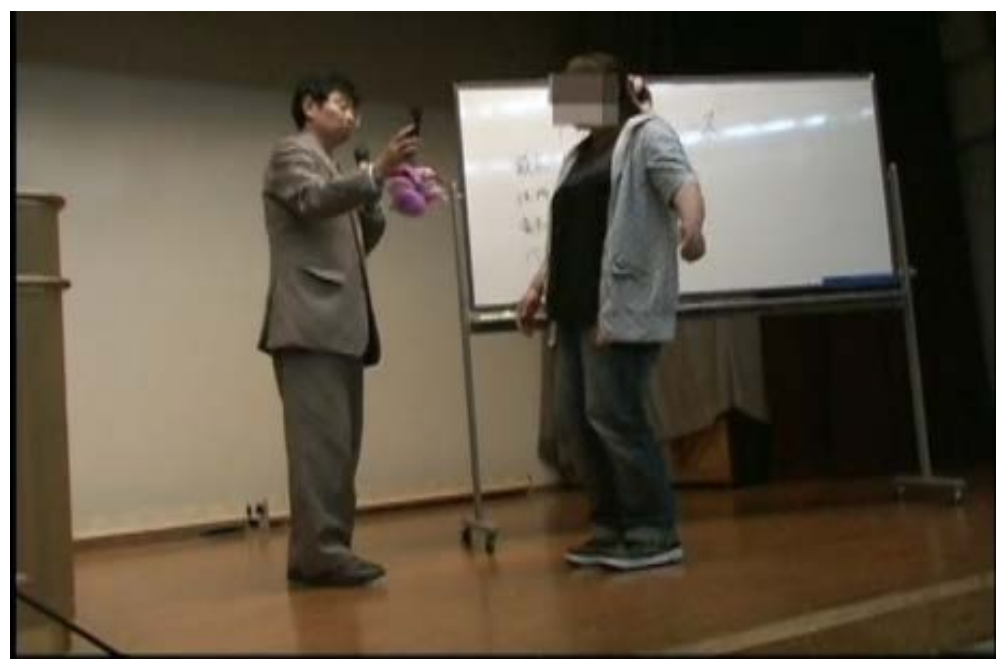

Figure 5. A loss of balance occurred in response to the electromagnetic waves emitted by a cell phone. The subject learned backward when the distance between the subject and the cell phone became $<50 \mathrm{~cm}$.

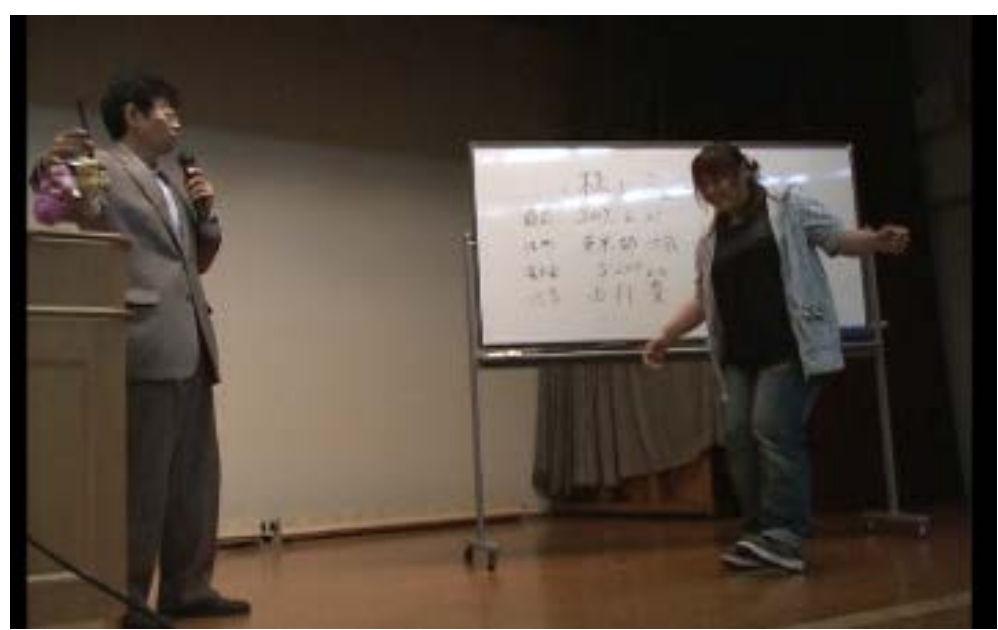

Figure 6. Placement of a dental implant worsened the subject's loss of balance. When a titanium implant was placed on the subject's chest, the subject leaned backward even at a distance $>3 \mathrm{~m}$ from the cell phone. 
The woman's unsteadiness appeared to be caused by electromagnetic waves from a cell phone and their interaction with the antenna-like behavior of a dental implant. Electromagnetic wave hypersensitivity onset does not merely result from the presence of harmful electromagnetic waves alone but from the waves combined with the existence of a material(s) that can act as an antenna by collecting harmful electromagnetic waves in or around the body. Dental implants may promote harmful effects of electromagnetic waves.

This patient volunteered to be treated in front of a large audience with the knowledge that the treatment was being videoed.

The details of this case can be observed in the following YouTube video:

Unsteadiness apparently caused by electromagnetic waves from a cell phone.

https://www.youtube.com/watch?v=csbaj6 mlkQ4 (last checked 2 May 2014).

\section{Discussion}

Regarding the relationship between brain tumors and radio waves emitted by cell phones, the Interphone Study Group concluded that no increases in the risk of glioma or meningioma associated with cell phone use were observed but that an increased risk of glioma was suggested at the highest usage levels. However, biases and error have prevented a causal interpretation; therefore, the possible effects of long-term heavy cell phone use will require further investigation [16]. In other reports, the published results do not support the hypothesis of an association between the use of cell phones and the development of brain or salivary gland tumors, leukemia, or other cancers [17]-[19]; however, the research described did not sufficiently evaluate the risks among long-term heavy cell phone users over potentially long induction periods [18]. Accordingly, further studies are needed to account for longer induction periods, particularly with respect to slow-growing tumors with neuronal features [19]. As such, the author has published several reports on the relationship between dentistry and electromagnetic waves [20]-[22]. Many articles, however, only emphasize the convenience of these electronic devices without addressing the potentially negative influences of the emitted electromagnetic waves on the body [23]. Metal present within the body can act as an antenna to collect harmful radio waves, thus inducing the aforementioned symptoms. In dentistry, titanium dental implants may be the material most commonly associated with antenna activity. The author previously reported that scoliosis may be caused by dental implants [20], and that electromagnetic waves emitted by cell phones can also affect balance disorders. The underlying mechanism remains unknown, but reduced blood flow within the brain is assumed [4]. This collection of unpleasant symptoms caused by electromagnetic waves is known as electromagnetic wave hypersensitivity. Generally, the electromagnetic wave strength decreases with distance even if near or far fields. In this experiment, the distance $3 \mathrm{~m}$ is situated in the Fraunh offer (far field) region, because the radio wave length of cell phones $(1-2 \mathrm{GHz})$ is $0.15-0.3 \mathrm{~m}$. The distance between cell phones and which border of near field is calculated with $\{\lambda /(2 \pi)\}$. Therefore, the distance from cellphones to the border of near field is about $2.5 \mathrm{~cm}$ to $5.0 \mathrm{~cm}$ from cell phones. Hence, $3 \mathrm{~m}$ is in the far field range, whereas the radio wave length from the PC screen $(50-60 \mathrm{~Hz})$ is $6000 \mathrm{~km}-5000 \mathrm{~km}$. Therefore, the distance from PC screen to the border of near field is about $830 \mathrm{~km}$ to $1000 \mathrm{~km}$. Hence, $3 \mathrm{~m}$ is in the region of Rayleigh (near field). However, the difference of effects among regions on the human bodies has not been clarified yet. Therefore, further research is required.

The author's research has shown that removal of metals which collect harmful electromagnetic waves from patients and maintaining sufficient distance from cell phones can reduce some of the harmful effects of electromagnetic waves and may permit short-duration, lower-risk usage of beneficial cell phone functions. The effects of electromagnetic waves on the body are not yet clear. As the author already suggested [20], the titanium implant collects the harmful electromagnetic radiation easier than pure gold. However, in terms of the SAR (Specific Absorption Rate) of the dental materials has hardly been explored yet. Regarding this point, the author results the cooperation between medical field and physical field is necessary. The underlying mechanism has been partially elucidated by the Bi-Digital O-Ring Test [24]. Because this test indicated deleterious effects of radio waves on the body [25] [26], it may be a useful diagnostic tool for helping to prevent harmful electromagnetic waves. One potential problem with these results is that the patient's knowledge of how close they were to the electromagnetic wave sources was not controlled. This could have led to some psychological influences. In future studies, blindfolding the patients could be used to eliminate this problem. According to the report of Hagström M. et al., the most common perceived EHS (Electromagnetic Hypersensitivity) triggering sources are personal computers and mobile phones. Additionally, the best way to reduce EHS symptoms was to avoid elec- 
tromagnetic fields [27]. The removal of dental material which collects harmful electromagnetic radiation is not well known. Hence, the contents introduced in this paper must be effective approach to treat EHS symptoms.

\section{Conclusion}

There have been many reports of individuals suffering from electromagnetic wave hypersensitivity. The current findings suggest that in addition to previously reported symptoms, including headaches, fatigue, tinnitus, dizziness, memory loss, irregular heartbeat, and whole-body skin symptoms, a sense of balance dysregulation or dyspnea is a symptom of electromagnetic wave hypersensitivity. Avoiding harmful electromagnetic waves is considered to reduce these physical symptoms and concomitantly improve physical abilities. Dental materials may act as antennae, and as such, may collect radio waves. Therefore, dental procedures should be performed with an awareness of this characteristic because some dental materials may cause or exacerbate adverse symptoms. Electromagnetic wave hypersensitivity could possibly be caused by dental procedures; therefore, dental treatment should be performed in a manner that avoids the harmful influences of radio waves on patients.

\section{References}

[1] Geser, H. (2004) Towards a Sociological Theory of the Mobile Phone, Release 3.0. University of Zurich. http://socio.ch/mobile/t_geser1.htm/

[2] van Dijk, J. and Hacker, K. (2003) The Digital Divide as a Complex and Dynamic Phenomenon. The Information Society, 19, 315-326. http://dx.doi.org/10.1080/01972240309487

[3] (2014) http://www.holistic-dentistry.net/blog/2013/07/entry_242/

[4] Aalto, S., Haarala, C., Brück, A., Sipilä, H., Hämäläinen, H. and Rinne, J.O. (2006) Mobile Phone Affects Cerebral Blood Flow in Humans. Journal of Cerebral Blood Flow and Metabolism, 26, 885-900. http://dx.doi.org/10.1038/sj.jcbfm.9600279

[5] Feychting, M., Jonsson, F., Pedersen, N.L. and Ahlbom, A. (2003) Occupational Magnetic Field Exposure and Neurodegenerative Disease. Epidemiology, 14, 413-419. http://dx.doi.org/10.1097/01.EDE.0000071409.23291.7b

[6] Håkansson, N., Gustavsson, P., Johansen, C. and Floderus, B. (2003) Neurodegenerative Diseases in Welders and Other Workers Exposed to High Levels of Magnetic Fields. Epidemiology, 14, 420-426. http://dx.doi.org/10.1097/01.EDE.0000078446.76859.c9

[7] Ahlbom, A. (2001) Neurodegenerative Diseases, Suicide and Depressive Symptoms in Relation to EMF. Bioelectromagnetics Supplement, 5, 132-143. http://dx.doi.org/10.1002/1521-186X(2001)22:5+<::AID-BEM1029>3.0.CO;2-V

[8] Linet, M.S., Hatch, E.E., Kleinerman, R.A., Robison, L.L., Kaune, W.T., Friedman, D.R., Severson, R.K., Haines, C.M., Hartsock, C.T., Niwa, S., Wacholder, S. and Tarone, R.E. (1997) Residential Exposure to Magnetic Fields and Acute Lymphoblastic Leukemia in Children. The New England Journal of Medicine, 337, 1-7. http://dx.doi.org/10.1056/NEJM199707033370101

[9] Röösli, M., Moser, M., Baldinini, Y., Meier, M. and Braun-Fahrländer, C. (2007) Symptoms of Ill Health Ascribed to Electromagnetic Field Exposure-A Questionnaire Survey. International Journal of Hygiene and Environmental Health, 207, 141-150. http://dx.doi.org/10.1078/1438-4639-00269

[10] Edelstyn, N. and Oldershaw, A. (2002) The Acute Effects of Exposure to the Electromagnetic Field Emitted by Mobile Phones on Human Attention. Neuroreport, 13, 119-121. http://dx.doi.org/10.1097/00001756-200201210-00028

[11] Rea, W., Pan, Y., Yenyves, E., Sujisawa, I., Suyama, H., Samadi, N. and Ross, G. (1991) Electromagnetic Field Sensitivity. Journal of Bioelectricity, 10, 241-256. http://www.feb.se/emfguru/Ehs/electromagnetic-sensitivity.html

[12] Rubin, G.J., Das Munshi, J. and Wessely, S. (2005) Electromagnetic Hypersensitivity: A Systematic Review of Provocation Studies. Psychosomatic Medicine, 67, 224-232. http://dx.doi.org/10.1097/01.psy.0000155664.13300.64

[13] Rubin, G.J., Das Munshi, J. and Wessely, S. (2006) A Systematic Review of Treatments for Electromagnetic Hypersensitivity. Psychosomatic Medicine, 75, 12-18.

[14] Norbert, L. (2009) Electromagnetic Hypersensitivity. Advances in Electromagnetic Fields in Living Systems, 5, 167197. http://dx.doi.org/10.1007/978-0-387-92736-7__5

[15] Kimata, H. (2005) Microwave Radiation from Cellular Phones Increases Allergen-Specific IgE Production. Allergy, 60, 838-839. http://dx.doi.org/10.1111/j.1398-9995.2005.00802.x

[16] Interphone Study Group (2010) Brain Tumor Risk in Relation to Mobile Telephone Use: Results of the Interphone International Case-Control Study. International Journal of Epidemiology, 39, 675-694. 
http://dx.doi.org/10.1093/ije/dyq079

[17] Johansen, C., Boice Jr., J.D., McLaughlin, J.K. and Olsen, J.H. (2001) Cellular Telephones and Cancer-A Nationwide Cohort Study in Denmark. Journal of the National Cancer Institute, 93, 203-207. http://dx.doi.org/10.1093/jnci/93.3.203

[18] Inskip, P.D., Tarone, R.E., Hatch, E.E., Wilcosky, T.C., Shapiro, W.R., Selker, R.G., Fine, H.A., Black, P.M., Loeffler, J.S. and Linet, M.S. (2001) Cellular-Telephone Use and Brain Tumors. The New England Journal of Medicine, 344, 79-86. http://dx.doi.org/10.1056/NEJM200101113440201

[19] Muscat, J.E., Malkin, M.G., Thompson, S., Shore, R.E., Stellman, S.D., McRee, D., Neugut, A.I. and Wynder, E.L. (2000) Handheld Cellular Telephone Use and Risk of Brain Cancer. Journal of the American Medical Association, 284, 3001-3007. http://dx.doi.org/10.1001/jama.284.23.3001

[20] Fujii, Y. (2012) Do Dental Implants Cause Scoliosis? A Case Report. Personalized Medicine Universe, 1, 79-80. http://dx.doi.org/10.1016/j.pmu.2012.05.012

[21] Fujii, Y. (2007) The Dental Treatment That Used Environment of Electromagnetic Wave. Acupuncture and ElectroTherapeutics Research, 32, 291.

[22] Fujii, Y. (2009) The Consideration of the Electromagnetic Wave in Dental Material Substitution. Acupuncture and Electro-Therapeutics Research, 34, 89.

[23] http://www.healthit.gov/providers-professionals/benefits-electronic-health-records-ehrs

[24] Omura, Y. (1990) Bi-Digital O-Ring Test for Imaging and Diagnosis of Internal Organs of a Patient. Patent No. 5188107.

[25] Omura, Y. and Losco, M. (1993) Electro-Magnetic Fields in the Home Environment (Color TV, Computer Monitor, Microwave Oven, Cellar Phone, etc.) as Potential Contributing Factors for the Induction of Oncogen C-Fos Ab1, Oncogen C-Fos Ab2, Integrin Alpha 5 Beta 1 and Development of Cancer, as Well as Effects of Microwave on Amino Acid Composition of Food and Living Human Brain. Acupuncture and Electro-Therapeutics Research, 18, 33-73.

[26] Omura, Y., Losco, M., Omura, A.K., Yamamoto, S., Ishikawa, H., Takeshige, C., Shimotsuura, Y. and Muteki, T. (1991) Chronic or Intractable Medical Problems Associated with Prolonged Exposure to Unsuspected Harmful Environmental Electric, Magnetic, or Electro-Magnetic Fields Radiating in the Bedroom or Workplace and Their Exacerbation by Intake of Harmful Light and Heavy Metals from Common Sources. Acupuncture and Electro-Therapeutics Research, 16, 143-177.

[27] Hagström, M., Auranen, J. and Ekman, R. (2013) Electromagnetic Hypersensitive Finns: Symptoms, Perceived Sources and Treatments, a Questionnaire Study. Pathophysiology, 20, 117-122. http://dx.doi.org/10.1016/j.pathophys.2013.02.001 
Scientific Research Publishing (SCIRP) is one of the largest Open Access journal publishers. It is currently publishing more than 200 open access, online, peer-reviewed journals covering a wide range of academic disciplines. SCIRP serves the worldwide academic communities and contributes to the progress and application of science with its publication.

Other selected journals from SCIRP are listed as below. Submit your manuscript to us via either submit@scirp.org or Online Submission Portal.
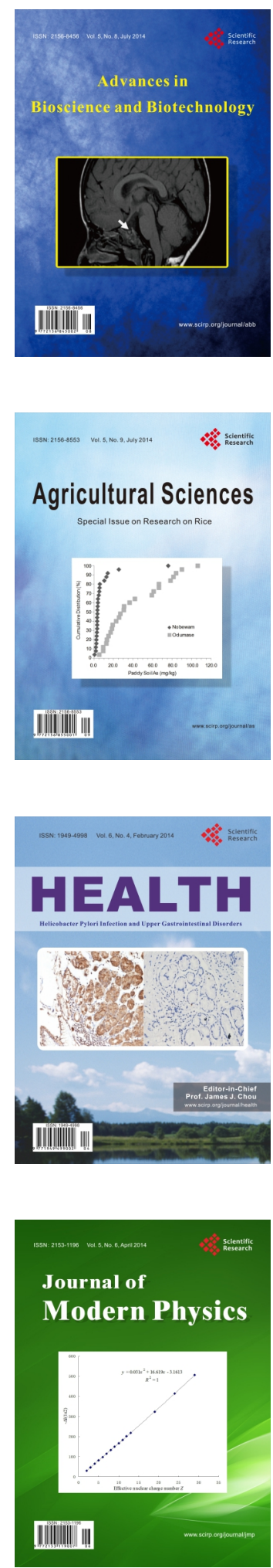
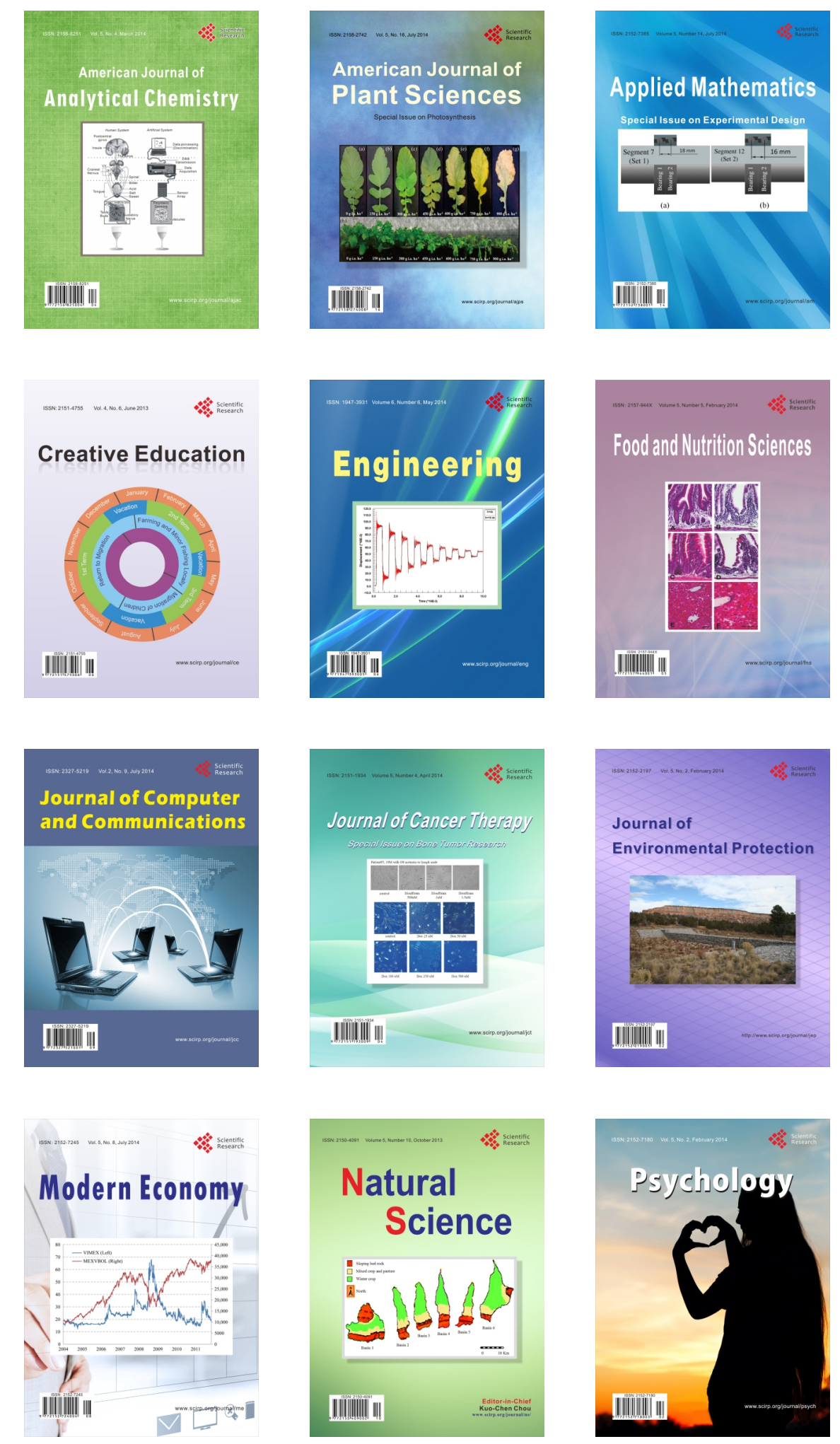